\title{
Radiation induced primary hypothyroidism: Expect the unexpected?
}

\author{
Adina Ghemigian $^{1,2}$, Andra Cocolos ${ }^{2}$, Nicoleta Dumitru², Mara Carsote1,2, Ana Valea ${ }^{3,4}$, \\ Eugenia Petrova ${ }^{1,2}$ \\ 1"Carol Davila" University of Medicine and Pharmacy, Bucharest, Romania \\ 2"C.I. Parhon" National Institute of Endocrinology, Bucharest, Romania \\ 3"Iuliu Hatieganu" University of Medicine and Pharmacy, Cluj-Napoca, Romania \\ ${ }^{4}$ Clinical County Hospital, Cluj-Napoca, Romania
}

\begin{abstract}
Adults and children who were exposed to head and/or neck radiotherapy for different cancers associate a life time higher risk than general population for a heterogeneous panel of secondary conditions like thyroid nodules, cancer and radiation induced primary hypothyroidism. We introduce an adult female case who was diagnosed and treated for Hodgkin lymphoma type IIB and one year after she presented non-autoimmune thyroiditis and high TSH. Hypothyroidism was substituted for 29 years; the ultrasound pattern remained hypoechoic with a relatively small gland and also associated radiation induced lung fibrosis.
\end{abstract}

Keywords: thyroid, TSH, radiation

\section{INTRODUCTION}

Adults and children who were exposed to head and/or neck radiotherapy for different cancers associate a life time higher risk than general population for a heterogeneous panel of secondary conditions from an endocrine point of view, for instance, thyroid nodules or thyroid malignancies (1-3). Because of this associated risk, the use of cervical ultrasound is necessary for long term follow-up in these patients $(1,2,4)$. However, there are reports of primary hypothyroidism (so called "radiation induced hypothyroidism") following neck radiotherapy (which is considered exclusive cause of it), thus the periodic check up of thyroid function after previous irradiation also seems useful; the best screening tool is TSH (Thyroid Stimulating Hormone) (5-7) (Fig. 1). We aim to introduce a case of real life medicine: an adult woman who developed thyroid hypo-function after radiotherapy for lymphoma. As method we mention that the paper is a case report. The patient was followed-up at different endocrinology centres and agreed for anonymously use of her medical records.

\section{CASE PRESENTATION}

This is a 58-year old non-smoking female. She comes from non-endemic area. Her medical history is irrelevant. Her personal medical history includes surgical menopause at age of 44 years because of uterine fibroma, and an episode of arrhythmia 3 years ago which required long time daily oral beta blockers. In 1989 she was confirmed with Hodgkin lymphoma type IIB, starting from a supra-clavicular lymph node enlargement. She had at that time surgery, chemotherapy and neck radiotherapy. One year later she was confirmed with primary hypothyroidism starting with suggestive clinical picture and confirmed based on TSH 4 times higher than upper normal limit. The patient had negative thyroid autoimmunity (thyroperoxidase antibodies of $10 \mathrm{UI} / \mathrm{ml}$, normal levels less than $35 \mathrm{UI} / \mathrm{ml}$ ). Thyroid ultrasound at that moment did not identify nodules larger than $1 \mathrm{~cm}$ (centimetre). The patient was offered daily morning levothyroxine therapy which required periodic TSH control.

At age of 54, she accused intermittent breathing troubles and an endocrine check-up was necessary. 


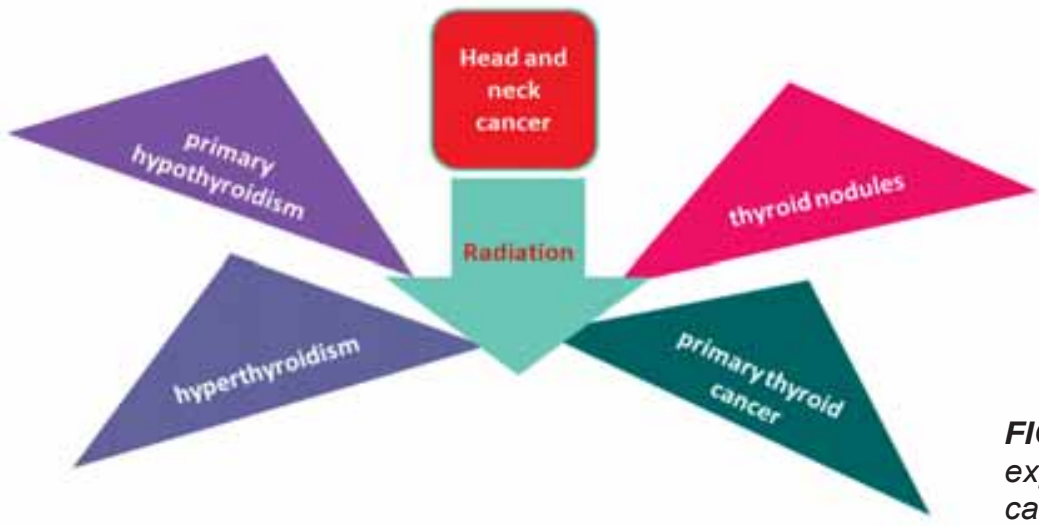

FIGURE 1. Thyroid conditions which may be expected after radiation for head and neck cancers of different types

TSH was normal (of $2.5 \mu \mathrm{UI} / \mathrm{ml}$, normal values between 0.5 and $4.5 \mu \mathrm{UI} / \mathrm{ml}$ ), so was the serum calcitonin (of $1 \mathrm{ng} / \mathrm{ml}$, normal levels below $3.8 \mathrm{ng} / \mathrm{ml}$ ), and thyroperoxidase antibodies (of $10 \mathrm{UI} / \mathrm{ml}$, normal levels below $35 \mathrm{UI} / \mathrm{ml}$ ). Thyroid ultrasound showed reduced diameters of the two lobes: right of 0.48 by 0.5 by $1.08 \mathrm{~cm}$, and left of 0.66 by 0.6 by $1 \mathrm{~cm}$, isthmus of $0.19 \mathrm{~cm}$, with hypoechoic pattern and no thyroid nodules, neither local lymph nodes enlargement. She associated low 25-hydroxyvitamin D levels of $21 \mathrm{ng} / \mathrm{ml}$ (normal levels above $30 \mathrm{ng} / \mathrm{ml}$ ) which required cholecalciferol therapy. Since no specific endocrine anomaly could explain the symptoms a computed tomography scan was done and pointed pulmonary fibrosis, most probably also secondary to prior radiation, and a small sub pleural nodule of 0.6 $\mathrm{cm}$ at left superior lobe. No oncologic interpretation was considered for this imagery aspect but annual imagery of the lung was done since then and pointed stationary aspects in addition to intermittent breathing anomalies which persisted.

During the current admission, clinical exam was status quo. Blood thyroid tests showed normal function (a TSH of $1 \mu \mathrm{UI} / \mathrm{ml}$, normal levels between 0.5 and $4.5 \mu \mathrm{UI} / \mathrm{ml}$, and FreeT4 of 15.2 $\mathrm{pmol} / 1$, normal between 10.3 and $24.4 \mathrm{pmol} / 1$ under daily $75 \mu \mathrm{g}$ of levothyroxine), negative thyroperoxidase antibodies, of $10 \mathrm{UI} / \mathrm{ml}$ (normal ranges between 0 and $35 \mathrm{UI} / \mathrm{ml}$ ), persistent low levels of 25-hydroxyvitamin $\mathrm{D}$, of $19 \mathrm{ng} / \mathrm{ml}$ (optimal levels above $30 \mathrm{ng} / \mathrm{ml}$ ). Thyroid ultrasound showed a right lob of 1.4 by 0.6 by $0.7 \mathrm{~cm}$, a left lobe of 2.3 by 0.9 by $0.7 \mathrm{~cm}$, a small nodule at left lobe of 0.6 by 0.4 by $0.4 \mathrm{~cm}$, no lymph nodes (Fig. 2).

\section{A. Longitudinal section}

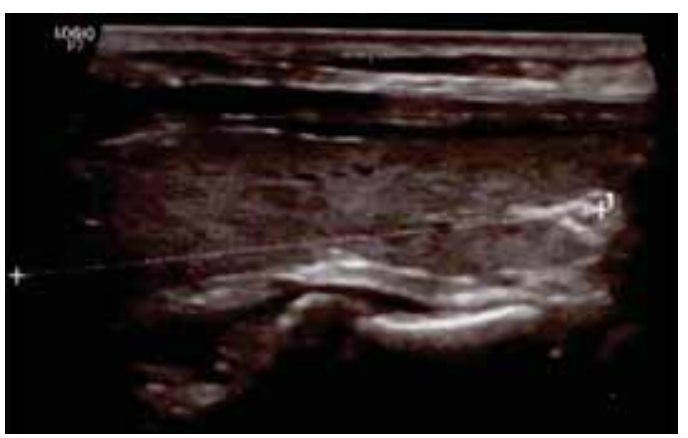

B. Longitudinal section

\section{Longitudinal section}

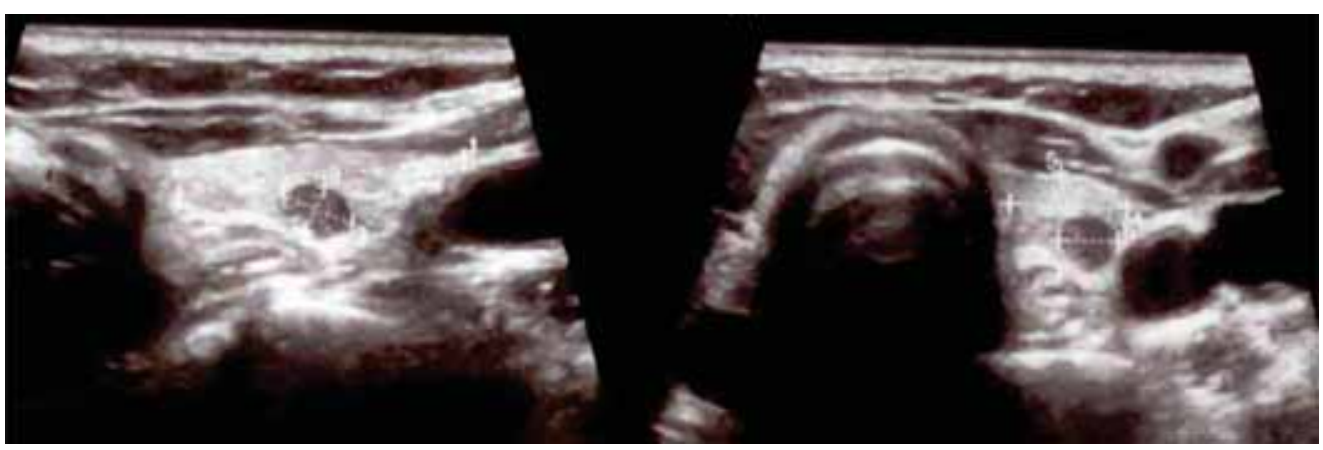

FIGURE 2. Thyroid ultrasound on a 58-year old female 29 years after therapy for Hodgkin lymphoma (which was followed by radiation induced primary hypothyroidism) reveals a right lobe of 1.4 by 0.6 by $0.7 \mathrm{~cm}$ (A), a left lobe of 2.3 by 0.9 by $0.7 \mathrm{~cm}(B), a$ small nodule at left lobe of 0.6 by 0.4 by $0.4 \mathrm{~cm}$. 


\section{DISCUSSION}

Primary hypothyroidism after head and neck radiotherapy represents a multidisciplinary topic, concerning oncology, endocrinology and primary health practitioners $(2,8)$. A review article included 2,449 papers on this topic (and finally 5 fulfilled rigorous inclusion/exclusion criteria of the review) of 57 up to 390 subjects who were enrolled in each study, and it highlighted that actually the primary hypothyroidism rate after neck radiotherapy is much higher than initially expected, approximately 23-53\% depending on irradiation dose but inter-individual variations are important (8). The effect of radiation on thyroid is complex, actually a process of radiotherapy-related thyroiditis is registered which also may associate transitory thyrotoxicosis, and a specific non-nodular pattern of thyroid ultrasound including changes of Doppler signal, hypoechogenicity and irregularity/lack of structure homogeneity (9). This particular type of thyroid deterioration primary targets the gland; especially the thyroid vessels, because of radiation itself and later the function anomalies are detected (9).

The occurrence of primary hypothyroidism after radiotherapy is not itself an exceptional event since typical causes as seen in general population like autoimmune chronic thyroiditis or endemic goitre related hypothyroidism but this type of condition underline a different mechanism due to radiation itself $(10,11)$. The rate of prevalence after radiotherapy is age-dependent (10-12). In the case we introduced, the patient was diagnose with radiation- associated hypothyroidism soon after oncologic/hematologic therapy was offered to the patient. There is not a specific time interval described since radiation exposure to the diagnosis of hypothyroidism depending on dose, and patient's background including suggestive symptoms of thyroid function anomalies and how often the patient had a routine TSH assay done. In this particular case, the clinical onset needed to be first differentiated from others malignancies including a primary thyroid lymphoma (13-15). One study on 120 survivors of head and neck cancers diagnosed during childhood with ages between 6 and 30 years pointed that $66 \%$ had consecutive thyroid diseases, and $27 \%$ of them had high TSH, $22 \%$ had nodules, $2 \%$ were confirmed with a secondary tumour as a thyroid cancer
(16). The risk of hypothyroidism increases with irradiation dose, with some particular types of cancers, including Hodgkin lymphoma as seen in our case (16). The advance of therapy for Hodgkin lymphoma increased the survival (almost $90 \%$ of patients have a long time survival) thus the risk of endocrine conditions is cumulative: a part from hypothyroidism, hyperthyroidism has been rarely described, the risk of thyroid malignancy starts 5-10 years after irradiation (17). Childhood Cancer Survivor Study included 13,674 subjects; survivors were diagnosed at a median of 14 years, and re-assessed at a median of 30 years (18). $34 \%$ of patients had a thyroid anomaly: hypothyroidism is the most frequent (relative risk of 17.1 versus controls) correlated with dose of irradiation, older age at diagnosis and female sex; the risk of hyperthyroidism is 8 times higher than controls, of thyroid nodules of 27 times, of thyroid cancer of 18 times (18). The first prospective of expected hypothyroidism after irradiation was published in 2012 and pointed a risk of 33\% within first 2 years (19). The effect is time dependent, not only dose dependent, and it appears within months to years, as a late complication of radiation dose $(20,21)$. Another risk factor seems to be the small gland volume, as seen in our case (20). The radiation induced thyroiditis is not associated with positive antibodies against thyroid as present case (22). We should also mention the fact that our patient developed another late complication of radiation: lung fibrosis. This condition may be expected early (less than 6 months) or late after thorax irradiation $(23,24)$. Radiation pneumonitis, if it comes years after cancer therapy, as seen in our case, more than 2 decades later, represents an exclusion diagnosis $(23,24)$. The patient also associated long time hypovitaminosis D despite intermittent supplements. This seems incidental most probably, due to geographic area of vitamin D deficiency (25).

\section{CONCLUSION}

The risk of radiation induced hypothyroidism increases with the dose and area of irradiation and it might be expected together with risk of developing thyroid nodules and even cancer thus ultrasound and TSH long time follow-up after head and neck cancers are essentials. 


\section{REFERENCES}

1. Kelly C., Rivard L., Salvi S., Hayani A., Hopkins W., O'Brien S., Martin L., Canner J. Surveillance following head, neck, and chest radiotherapy: thyroid ultrasound monitoring for secondary thyroid malignancy. Pediatr Blood Cancer. 2013 Jan; 60(1):140-2.

2. Dumitru N., Ghemigian A., Carsote M., Albu S.E., Terzea D., Valea A. Thyroid nodules after initial evaluation by primary health care practitioners: an ultrasound pictorial essay. Archives of the Balkan Medical Union. 2016; 51(3):434-438.

3. Brignardello E., Felicetti F., Castiglione A., Gallo M., Maletta F., Isolato G., Biasin E., Fagioli F., Corrias A, Palestini N. Ultrasound surveillance for radiation-induced thyroid carcinoma in adult survivors of childhood cancer. Eur J Cancer. 2016 Mar; 55:74-80.

4. Li Z., Franklin J., Zelcer S., Sexton T., Husein M. Ultrasound surveillance for thyroid malignancies in survivors of childhood cancer following radiotherapy: A single institutional experience. Thyroid. 2014 Dec; 24(12):1796-805.

5. Smit M., Kerstens M.N., Boomsma-van Holten M.J., van der Meer K., Zijlstra J.G., Links T.P. Hypothyroidism after radiotherapy of the neck area: Monitoring of thyroid function is important. Ned Tijdschr Geneeskd. 2014; 158:A6714.

6. Akgun Z., Atasoy B.M., Ozen Z., Yavuz D., Gulluoglu B., Sengoz M., Abacioglu U. V30 as a predictor for radiation-induced hypothyroidism: A dosimetric analysis in patients who received radiotherapy to the neck. Radiat Oncol. 2014 May 2;9:104.

7. Kim M.Y., Yu T., Wu H.G. Dose-volumetric parameters for predicting hypothyroidism after radiotherapy for head and neckcancer. Jpn J Clin Oncol. 2014 Apr; 44(4):331-7.

8. Boomsma M.J., Bijl H.P., Langendijk J.A. Radiation-induced hypothyroidism in head and neck cancer patients: A systematic review. Radiother Oncol. 2011 Apr; 99(1):1-5.

9. Bakhshandeh M., Hashemi B., Mahdavi S.R., Nikoofar A., Edraki H.R., Kazemnejad A. Evaluation of thyroid disorders during head-and-neck radiotherapy by using functional analysis and ultrasonography. Int J Radiat Oncol Biol Phys. 2012 May 1; 83(1):198-203.

10. Faggiano A., Del Prete M., Marciello F., Marotta V., Ramundo V., Colao A. Thyroid diseases in elderly. Minerva Endocrinol. 2011 Sep; 36(3):211-31.

11. Valea A., Ghervan C., Morar A., Pop D.D., Carsote M., Albu S.E., Georgescu C.E., Chiorean A. Hashimoto's thyroiditis and breast cancer: Coincidence or correlation? Archives of Balkan Medical Union. 2016; 51(1):129-132.

12. Jereczek-Fossa B.A., Alterio D., Jassem J., Gibelli B., Tradati N., Orecchia R. Radiotherapy-induced thyroid disorders. Cancer Treat Rev. 2004 Jun; 30(4):369-84.
13. Sarinah B., Hisham A.N. Primary lymphoma of the thyroid: diagnostic and therapeutic considerations. Asian J Surg. 2010 Jan; 33(1):20-4.

14. Mancuso S., Carlisi M., Napolitano M., Siragusa S. Lymphomas and thyroid: Bridging the gap. Hematol Oncol. 2018 Feb 27. doi: 10.1002/hon.2504. [Epub ahead of print]

15. Pavlidis E.T., Pavlidis T.E. A Review of Primary Thyroid Lymphoma: Molecular Factors, Diagnosis and Management. J Invest Surg. 2017 Oct 23:1-6.

16. Çağlar A.A., Oğuz A., Pınarlı F.G., Karadeniz C., Okur A., Bideci A., Koçak Ü., Bora H. Thyroid abnormalities in survivors of childhood cancer. J Clin Res Pediatr Endocrinol. 2014 Sep; 6(3):144-51.

17. Rodriquez D.C., Guidoni E., D'ambrosio A., Pochiero F., Caini M., Guglielmucci D., Lucherini M., Carra F., Municchi G. Abnormalities of the thyroid in survivors of childhood Hodgkin's disease. Minerva Pediatr. 2014 Aug; 66(4):249-56.

18. Sklar C., Whitton J., Mertens A., Stovall M., Green D., Marina N., Greffe B., Wolden S., Robison L. Abnormalities of the thyroid in survivors of Hodgkin's disease: data from the Childhood Cancer Survivor Study. J Clin Endocrinol Metab. 2000 Sep; 85(9):3227-32.

19. Boomsma M.J., Bijl H.P., Christianen M.E., Beetz I., Chouvalova O., Steenbakkers R.J. et al. A prospective cohort study on radiation-induced hypothyroidism: Development of an NTCP model. Int J Radiat Oncol Biol Phys. 2012 Nov 1; 84(3):e351-6.

20. Feen Rønjom M. Radiation-induced hypothyroidism after treatment of head and neck cancer. Dan Med J. 2016 Mar; 63(3). pii: B5213.

21. Bakhshandeh M., Hashemi B., Mahdavi S.R., Nikoofar A., Vasheghani M., Kazemnejad A. Normal tissue complication probability modeling of radiation-induced hypothyroidism after head-and-neck radiation therapy. Int J Radiat Oncol Biol Phys. 2013 Feb 1; 85(2):514-21.

22. Ferrari S.M., Fallahi P., Antonelli A., Benvenga S. Environmental Issues in Thyroid Diseases. Front Endocrinol (Lausanne). 2017 Mar 20; 8:50.

23. Giridhar P., Mallick S., Rath G.K., Julka P.K. Radiation induced lung injury: Prediction, assessment and management. Asian Pac J Cancer Prev. 2015; 16(7):2613-7.

24. Ding N.H., Li J.J., Sun L.Q. Molecular mechanisms and treatment of radiation-induced lung fibrosis. Curr Drug Targets. 2013 Oct; 14(11):1347-56.

25. Albu S.E., Geleriu A., Carsote M., Mihai A., Vasiliu C., Poiana C. The vitamin D status in menopausal women. Archives of Balkan Medical Union. 2015; 50(2):275-277. 